\title{
Effect of Additives on UV-Activated Urethane Acrylate Polymerization Composite Coatings
}

\section{Zane GRIGALE-SOROCINA ${ }^{1}{ }^{*}$, Martins KALNINS ${ }^{1}$, Jana SIMANOVSKA ${ }^{2}$, Elīna VINDEDZE ${ }^{2}$, Ingmars BIRKS ${ }^{2}$, Evita BRAZDAUSKA ${ }^{2}$}

\author{
${ }^{1}$ Riga Technical University, Faculty of Material Science and Applied Chemistry, Institute of Polymer Materials, Paula \\ Valdena Street 3, Riga, LV-1048, Latvia \\ ${ }^{2}$ Environment, Bioenergetics and Biotechnology Competence Centre, Aizkraukles street 21, 339, Riga, LV-1006, Latvia
}

cross $^{\text {ref }}$ http://dx.doi.org/10.5755/j01.ms.22.1.7442

Received 26 June 2014; accepted 20 February 2015

\begin{abstract}
An increased demand for new and improved coating systems, for environmental \& health \& safety and performance reasons, have appeared during the recent decades. Currently, there is new interest in preparation of thin UV curable urethane acrylate (UA) composite coatings with short-term properties. Cellulose based additives: nitrocellulose, cellulose acetate butyrate, sucrose benzoate and silica were evaluated to determine their influence on unreacted composite characteristics (viscosity, pigment suspension stability) and characteristics of cured film (ultimate tensile strength, elongation at break, surface gloss, surface scratch resistance and film adhesion loss time). The most suitable additive content was found to provide required viscosity. All additives increase surface scratch resistance, but cellulose based additives increase surface gloss values and decrease the time of adhesion loss. Silica has great effect on the interaction between linear and hyperbranched urethane acrylates, which has crucial influence on the stability of uncured pigmented mixture samples.

Keywords: UV-curable, coatings, photopolymerization, urethane acrylate.
\end{abstract}

\section{INTRODUCTION}

Light induced curing in polymer coating systems has been intensively studied because of its association with environmental protection, lower energy consumption and rapid curing even at the room temperature [1]. Compared to thermally cured coatings, the use of UV-radiation curable coatings offers advantages, such as instant drying, broad formulating range, reduced energy consumption and coating of heat sensitive substrate [2]. Therefore, UVcuring technology has been considered as an alternative to traditional solvent-borne coatings, because of its ecocompatible manufacturing process and excellent properties, such as high hardness, gloss, scratch and chemical resistance [1]. The main components of UV curable photopolymer compositions are monomers, oligomers, and photoinitiators. Most commercially used UV curable compositions are based on acrylic functional monomers and oligomers [3]. Their properties are influenced by their functionality, the type of isocyanate, and the type and molecular weight of polyol used in the synthesis. The higher functionality gives greater reactivity and harder cured films with good scratch and chemical resistance, but at the same time causes increase of resin viscosity [4]. The monomer is used to control formulation viscosity (reactive diluent) but it affects both the cure speed and the extent of polymerization, and the properties of the cured film. Some of the commonly used acrylic monomers (especially the multifunctional acrylic monomers) have a strong odor, and are skin and eye irritants. Due to their low molecular weight, additional

\footnotetext{
${ }^{*}$ Corresponding author. Tel.: +371 28323467.

E-mail address: zane.grigale@gmail.com (Z. Grigale-Sorocina)
}

problems may arise as there could be a high amount of extractables and considerable shrinkage could occur. This causes poor adhesion to substrate [5]. The chemical structure of the monomers and oligomers determines the physical properties of the formulation before and after curing [6]. Photoinitiation is one of the most efficient methods for achieving quasi-instantaneous polymerization as it transforms a liquid molecule into a solid polymer material in less than 1s [7]. The high reactivity of acrylate monomers and oligomers means that radical-type polymerization can be initiated with only a small amount of photoinitiators (Fig. 1) [3].

Increased demands for new and improved coating systems, for both environmental and performance reasons, have appeared during recent decades. Techniques such as low temperature curing systems, and high-solids have gained increased interest and obtained significant market shares. Although improved in many aspects, for technical reasons, these systems still have limited use in certain applications [8]. Efficient way to improve the properties of uncured system as thixotropy, anti-sedimentation, pigment wetting is supplementing the composite material with different additives $[9,10,11]$. Coating additives belong to a broad and diffuse category of key components used in a coating formulation. The function of any additive is very specific in nature and provides a range of properties to a coating [12]. There are few articles in the scientific literature about additives for UV curing coatings, although they are widely used in the industry. The most reported additive is nano-silica, which has been widely used in coating industries to decrease pigment particle sedimentation and surface leveling [13] because interfacial interactions $[9,14]$. 


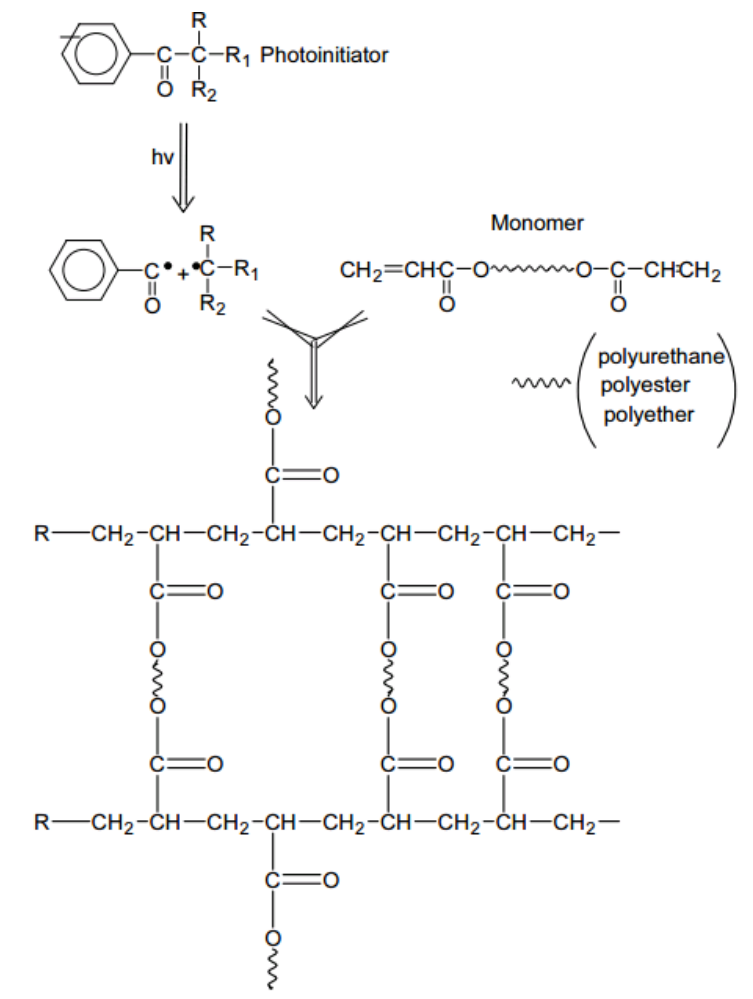

Fig. 1. UV-induced radical polymerization of a diacrylate monomer leading to a photo cross-linked polyacrylate network [3]

All previous studies have focused on creating coatings with long-term properties, but in recent years the coating industry has devoted much research in the direction of making eco-friendly coating material [2]. Cellulose derivatives [10], chitosan and other biopolymers [15] are of interest in improving the composite eco-profile $[16,17]$, especially when these applications are designed for medicine, dentistry and cosmetics $[12,15,17]$.

In the last decade new market space for coating applications with short-term requirements has appeared. The market space includes medicine and cosmetics such as natural nail coatings $[18,19]$. Short-term coating applications haven't been reported yet, only some patent applications have been submitted [20,21, 22]. The formulation of appropriate coatings is critical to achieve not only adhesion loss from substrate (within 5-30 min after treatment by cosmetically permitted solvent acetone) but also pigment suspension stability, reduced viscosity (3000-4500 mPas), increased deformability (tensile strain $40-150 \%$ ), degree of conversion $(50-90 \%)$ and high surface gloss (>70 GU). Novel additives have been searched to ensure the required characteristics and easy removability from the substrate after loss of functionality. The aim of this study was to improve specific coating application characteristics and to optimize the composition of a system composed of urethane acrylate oligomers, monomer, photoinitiator by addition of different supplements.

\section{EXPERIMENTAL}

\subsection{Materials}

Different formulations of the UV curable coating consisting of urethane acrylate oligomers, monomer and photoiniciator were studied. Hydroxypropylmethacrylate (HPMA) (Esstech, USA) was used as a monomer (Fig. 2) (Purity > $97 \%$, Inhibitor MeHQ 225 ppm). Photoiniciator ethyl -2,4,6-Trimethylbenzoylphenylphosphinate (Lucirin TPO_L) (BASF, Germany) was applied for the initiation of radical photopolymerization reactions. Its chemical structure (Fig. 3) and absorbance spectrum (Fig. 4) are shown below. Three different commercially available difunctional urethane acrylate oligomers were used for film forming: Exothane 8, Exothane 10 and Exothane 26 (Esstech, USA). Their main properties are shown in Table 1. Cured oligomers are characterized by rather high deformability (elongation at break 40-80\%).

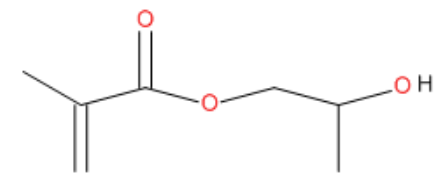

Fig. 2. Chemical structure of HPMA

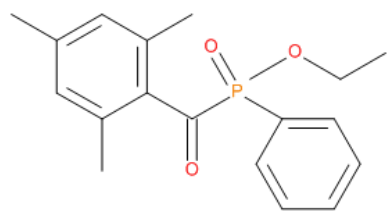

Fig. 3. Chemical structure of Lucirin TPO_L

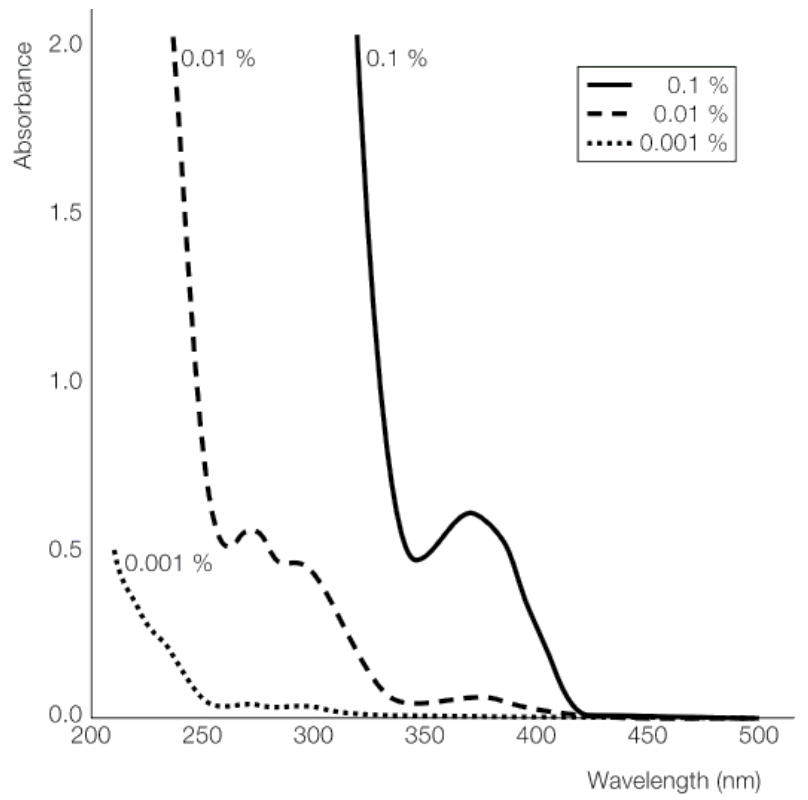

Fig. 4. Absorbance spectrum of Lucirin TPO-L in Ethanol

Four different additives were evaluated. Nitrocellulose E400 (NC) (DOW Europe, Switzerland) (molecular weight 400, film elongation at break 5-10\%, tear resistance $59-69 \mathrm{~N} / \mathrm{mm}^{2}$ ) and cellulose acetate butyrate (CAB) (CAB-551-0.2) (Eastman, The Netherlands) (molecular weight 30000 , melting point $130-140{ }^{\circ} \mathrm{C}$, glass transition $\mathrm{T}=101{ }^{\circ} \mathrm{C}$ ) were selected as film former additives. Both of these additives were chosen to ensure the easier coating removability. Sucrose benzoate (SB) Miramer SB (Miwon, Corea) was chosen due to their excellent UV stability, unusual clarity and low solution viscosity [20,21]. Fumed silica HDK H15 (Wacker, Germany) (BET surface area $175-225 \mathrm{~m}^{2} / \mathrm{g}$, refraction index at $20{ }^{\circ} \mathrm{C} 1.46$ ) was chosen 
to reduce pigment particle sedimentation and to improve surface leveling.

Table 1. Major properties of base oligomers Exothane 8, Exothane 10 and Exothane 26[AH1]

\begin{tabular}{|l|c|c|c|}
\hline Property & Exothane 8 & Exothane 26 & Exothane 10 \\
\hline \multicolumn{3}{|c|}{ uncured } \\
\hline $\begin{array}{l}\text { Molecular } \\
\text { weight }\end{array}$ & $600-1300$ & $700-1400$ & $400-1000$ \\
\hline Inhibitors & $\begin{array}{c}\text { MeHQ*- } \\
8 \mathrm{ppm}\end{array}$ & $\begin{array}{c}\text { MeHQ-22 } \\
\text { ppm }\end{array}$ & $\begin{array}{c}\text { MeHQ-29 } \\
\text { ppm }\end{array}$ \\
\cline { 2 - 4 } & $\begin{array}{c}\text { BHT**- } \\
584 \mathrm{ppm}\end{array}$ & $\begin{array}{c}\text { BHT }-586 \\
\text { ppm }\end{array}$ & $\begin{array}{c}\text { BHT-3730 } \\
\text { ppm }\end{array}$ \\
\hline Viscosity (PaS) & 30110 & 15510 & 70000 \\
\hline \multicolumn{4}{|c|}{ cured } \\
\hline $\begin{array}{l}\text { Ultimate stress } \\
\text { (MPa) }\end{array}$ & 345 & 125 & 607 \\
\hline $\begin{array}{l}\text { Tensile strength } \\
\text { (MPa) }\end{array}$ & 17 & 6 & 29 \\
\hline $\begin{array}{l}\text { Tensile elastic } \\
\text { modulus (GPa) }\end{array}$ & 76.1 & 17 & 345 \\
\hline $\begin{array}{l}\text { Elongation at } \\
\text { break (\%) }\end{array}$ & 79 & 46 & 64 \\
\hline $\begin{array}{l}\text { MeHQ* - Mono Methyl Ether of Hydroquinone } \\
\text { BHT**-Butylated Hydroxytoluene }\end{array}$ \\
\hline
\end{tabular}

\subsection{Sample preparation}

To avoid premature polymerization, each composition was mixed in a round bottom flask in yellow $(570-590 \mathrm{~nm})$ light. Preliminary tests were performed to find the best technology to bring the additive into the mixture and to evaluate the optimal concentration of each additive. All additives in the concentration range $0.5-3.0$ wt. $\%$ (as \% of total mixture) were mixed by mechanical stirring $(100-3000 \mathrm{rpm})$ in monomer, at temperature $50{ }^{\circ} \mathrm{C}$ for $5-60 \mathrm{~min}$ to achieve a fully dispersed premix. Microscope Model DC5-420TH was used for visual inspections to evaluate mixture homogeneity. After premix, prepared definite content (26wt.\%) of each oligomer, monomer (20 wt.\%) and photoinitiator ( $2 \mathrm{wt} . \%$ ) were added and blends were further stirred at $100 \mathrm{rpm}$ at ambient temperature for $30 \mathrm{~min}$. After preparation, systems were stored at $40{ }^{\circ} \mathrm{C}$ for $12 \mathrm{~h}$ to lose air inclusions. Further, mixed gel was used for stability tests or was applied on substrate, cured and films were obtained.

\subsection{Coating formation}

The coating was formed on the surface of acetone treated Teflon sheets or Aluminum sheets by use of Bykodrive applicator from BYK Gardner with the rate $10 \mathrm{~mm} / \mathrm{s}$ to reach film thickness $200 \mu \mathrm{m}$. The coating was cured under UV lamp KP800LED (luminous intensity $130 \mathrm{mw}$, $\lambda=405 \mathrm{~nm}$ ) (YI Liang electron technology Co, China) for $30 \mathrm{~s}$. The curing time of photopolymers is dependent upon the dose intensity and wavelength of the UV light. Initiation of polymerization requires precise matching of photoiniciator and UV light source [1]. To avoid oxygen inhibition activity on the curing in coating surface, it was coated with transparent PE film with thickness $50 \mu \mathrm{m}$. After curing PE film was removed.

\subsection{Design of the experiments}

Evidently additives will influence all characteristics of both the uncured mixture and the cured coating. Therefore in this work firstly viscosity and pigment suspension stability tests were performed to determine the optimal additive concentration. Based on the test results the best compositions were chosen for further tests, which are shown in Table 2: performed tests for uncured mixture and cured coating.

Table 2. Characteristics and relevant evaluation methods

\begin{tabular}{|l|l|}
\hline \multicolumn{2}{|c|}{ Mixture } \\
\hline \multicolumn{1}{|c|}{ Characteristic } & \multicolumn{1}{c|}{ Method } \\
\hline Pigment suspension stability & Stability test at $40^{\circ} \mathrm{C}$ \\
\hline Viscosity & Brookfield viscosity \\
\hline Degree of conversion & Gel fraction determination \\
\hline \multicolumn{2}{|c|}{ Coating } \\
\hline \multicolumn{2}{|c|}{ Characteristic } \\
\hline Adhesion loss & Soak off in acetone \\
\hline Scratch resistance & SAM \\
\hline Strength deformation & Tensile tests \\
\hline
\end{tabular}

\subsection{Test methods}

To evaluate additive effect on pigment suspension sedimentation stability, tests on pigmented uncured mixtures were performed with $2 \%$ white pigment $\mathrm{TiO}_{2}$ (Durlin, France) and $0.01 \%$ red pigment (RED 403, Kromachem, Germany) $40{ }^{\circ} \mathrm{C}$ for 4 weeks. After each 7 day period pigment sedimentation was evaluated optically. The test was considered to be passed if after 4 weeks there was no difference in the color of the mixture and pigment sedimentation wasn't observed.

Coating adhesion loss was evaluated using $95 \%$ acetone solution in water. $200 \mu \mathrm{m}$ of uncured mixture was applied on aluminum sheets (on area $3 \mathrm{~cm} \times 3 \mathrm{~cm}$ ), and cured under UV lamp for $30 \mathrm{~s}$. Cured coatings were wrapped in paper pads impregnated with acetone, coated in aluminum foil $(100 \mu \mathrm{m}$ thickness $)$ to avoid solvent evaporation and kept for 5-30 minutes. Adhesion of coating on the substrate was measured with SAM (Scratch Adhesion and Mar Tester) device S.A.M PA-5050 (Gardco, USA) where the Hoffman tester concept is used [24]. After each 2.5 minutes period, coating adhesion to the substrate was evaluated using 5 SAM scratches (with distance $5 \mathrm{~mm}$, force $250 \mathrm{~g}$ ) longitudinal and transversely. Effective soak-off time was detected when $100 \%$ adhesion loss between substrate and coating is ascertained.

Additive effect on uncured urethane acrylate viscosity was determined by Brookfield viscometer DV-II+ Pro (Brookfield Engineering Laboratories, USA). Needle was used according to the composition tested. Three parallel measurements for each composition were made at $100 \mathrm{rpm}$, measuring for 3 minutes and recording results with a time interval of 30 seconds. Average result from the measurements was taken.

Scratch resistance to evaluate the additive influence on coating surface was measured with SAM device S.A.M PA-5050 (Gardco, USA). The trolley is pulled across the test sample and the effect, if any, of the "blade" is observed. SAM was used in the lower range of up to 
250 grams and the imprint was measured on a 20-point scale marked on the SAM device according to STP 500, 5.1.2.5, Paint Testing Manual, published by the ASTM [24].

The mechanical properties of UV-cured films were determined by standard tensile stress-strain tests to measure ultimate tensile strength $\left(\sigma_{\max }\right)$ and elongation at break $\left(\varepsilon_{\mathrm{b}}\right)$. Standard tensile stress-strain experiments were performed at room temperature on Tensile tester BDO FB020TN (Zwick Roell, Germany) according to requirements $[25,26]$ (sample shape: double blade films; the speed of the upper cross-head: $10 \mathrm{~mm} / \mathrm{min}$ ). The results present the mean values of five independent measurements.

The gloss measurements were carried out using the Novo Gloss Lite Gloss Meter (Rhopoint Instruments Ltd., Great Britain) at an angle of $60^{\circ}$.

Gel fraction was used as characteristic of degree of conversion in polymerization reaction. The gel fraction is measured by Soxhlet-type extraction in acetone for 8 hours and by drying the extracted gel until it has a constant weight in vacuum. The gel fraction is then calculated as a ratio of the weight of the acetone-insoluble part and the feed monomer and oligomer [27, 26].

\section{RESULTS AND DISCUSSION}

At the beginning of the experiments the best incorporation technology for additives was found using visual inspections with the microscope. It was found that additives such as $\mathrm{NC}, \mathrm{CAB}$ and $\mathrm{SB}$ can be mixed in monomer with low shear rate stirring $(100-300 \mathrm{rpm})$ and for shorter periods of time (10 min), but silica needs to be dispersed in monomer with high shear rotation $(3000 \mathrm{rpm})$ for $30 \mathrm{~min}$ to achieve full dispersity of silica particles in acrylate gel.

Secondly suitable additive concentrations were determined. Uncured composition should prevent pigment particle sedimentation and viscosity should be less than $4500 \mathrm{mPas}$. $\mathrm{NC}$ and $\mathrm{CAB}$ in concentrations $2 \%$ can efficiently prevent the pigment particle sedimentation.

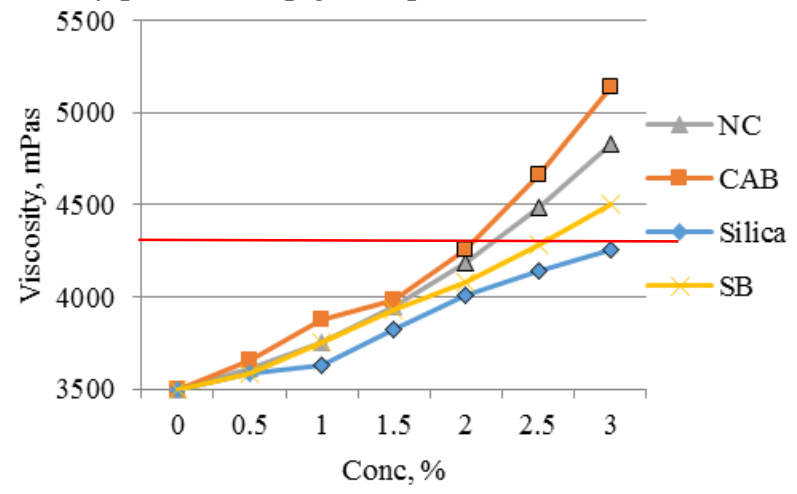

Fig. 5. The influence of additive content on UA base viscosity and pigment suspension stability. Stable concentrations are marked with black line around the point. Red line indicates the highest possible viscosity[AH2]

As higher concentrations of these additives strongly increase system viscosity (Fig. 5), $2 \%$ was chosen as appropriate additive concentration. Silica already at $1 \%$ can prevent the pigment particle sedimentation. This system also has the smallest viscosity, what makes the coating application more convenient, therefore suitable concentration for it is found to be $1 \%$. Silica already previously have been described as effective gelling agent for pigmented systems $[11,13]$. Compositions with additive $\mathrm{SB}$ in concentration range $0-3 \%$ cannot prevent the particle sedimentation, therefore test concentration was chosen using viscosity data and effective soak off time, were the compromise between them is for the systems with $2 \% \mathrm{SB}$.

Further adhesion loss from the substrate was studied. Pure base needs $25 \mathrm{~min}$ in acetone medium to lose the adhesion from the substrate. All additives decrease the soak off time. $\mathrm{NC}$ and $\mathrm{CAB}$ gave the highest influence on adhesion loss after solvent treatment, decreasing the destruction time from $25 \mathrm{~min}$ to $15 \mathrm{~min}$ ( $2 \%$ of additives) (Fig. 6 a). All additives improve surface scratch resistance data compared to pure urethane acrylate base (Fig. 6 b).
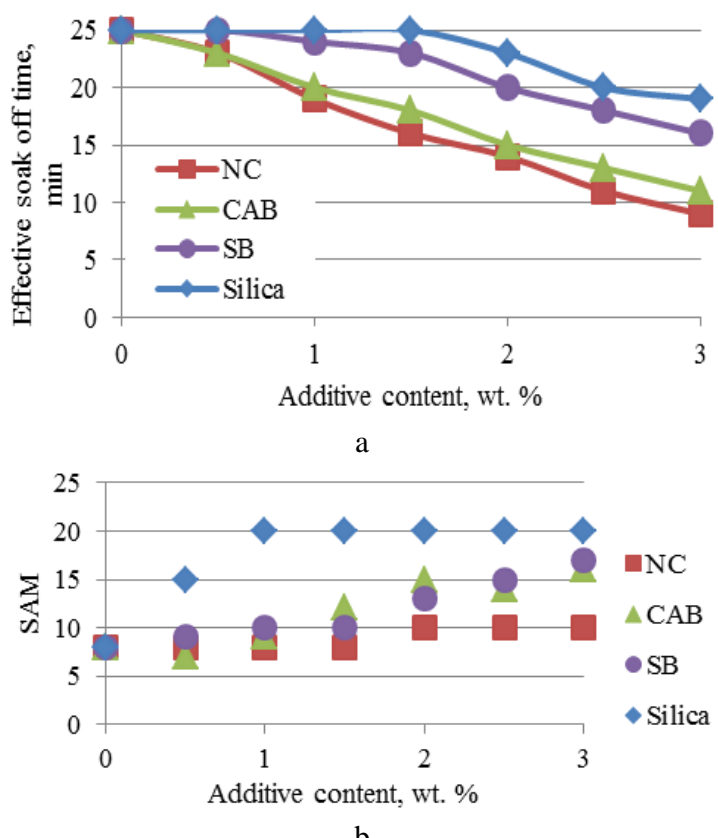

Fig. 6. Additive content influence on coating soak off time (a) and surface abrasion resistance (b)

The highest impact on surface scratch resistance was shown by silica (increase 2.5 times). Due to smaller particle size silica can fill free space between polymer molecules and behave as a surface additive. $\mathrm{CAB}$ and SB can be considered as potential additives for surface coating, as increasing amount of them increases surface scratch resistance.

Degree of conversion was determined by evaluation of gel fraction values. These data can explain the adhesion loss results, showing correlation between degree of conversion and effective soak off time (Fig. 7 a). Compositions with $\mathrm{NC}$ and $\mathrm{CAB}$ have the smallest gel fraction values, therefore additives promote faster adhesion loss. The stress $(\sigma)$-strain $(\varepsilon)$ curves of the UV cured samples were taken. Initial elastic modulus

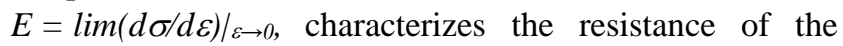
initial structure of the polymer at low unit strain values, when structure transformations nearly have not yet occurred [4]. There is a significant drop of E values with addition of various additives (Table 3 ). 
Table 3. Additive influence on film modulus of elasticity, elongation at break and surface gloss at $60^{\circ}$

\begin{tabular}{|l|c|c|c|c|}
\hline Additive & $E, \mathrm{MPa}$ & $\varepsilon b, \%$ & $\sigma_{\max ,}, \mathrm{MPa}$ & Surface gloss, GU \\
\hline No & 484 & 52 & 31 & 54 \\
\hline Silica & 475 & 24 & 31 & 51 \\
\hline NC & 250 & 9 & 19 & 68 \\
\hline CAB & 350 & 46 & 21 & 84 \\
\hline SB & 277 & 40 & 24 & 86 \\
\hline
\end{tabular}

They strongly reduce the value of $\sigma_{\max }$ and the value of $\varepsilon_{\text {break }}$ There is also correlation between values of $\sigma_{\max }$ and degree of conversion (Fig. 7 b).

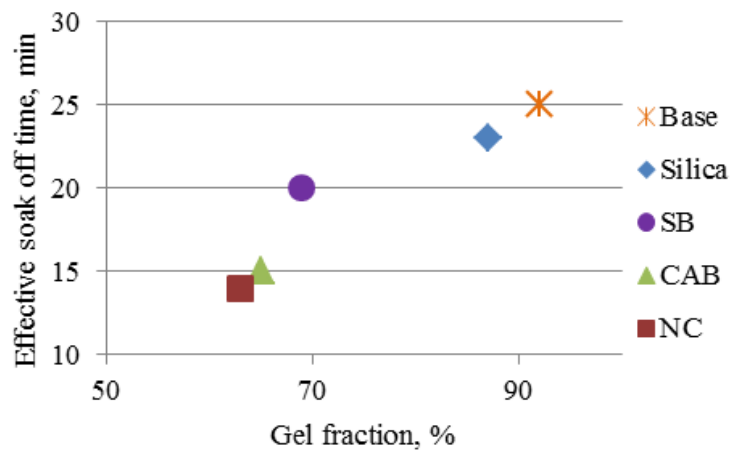

a

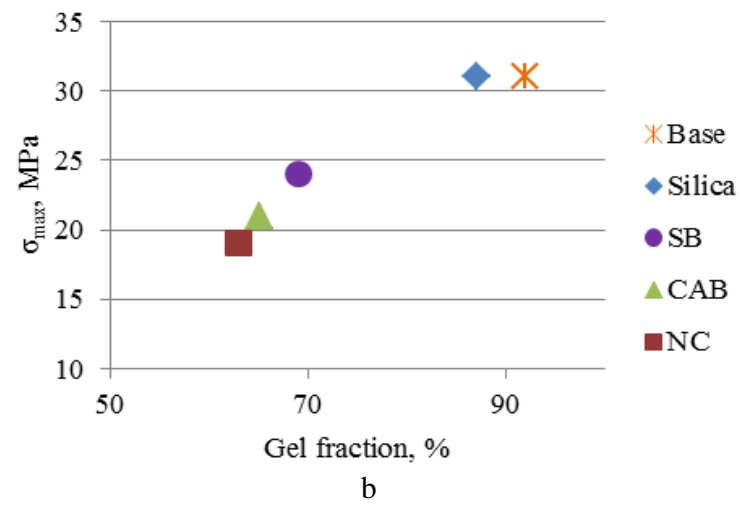

Fig. 7. Gel fraction data correlation with effective soak off time (a) and Ultimate strength (b) for compositions with $1 \%$ of silica, $2 \%$ of SB, CAB and NC comparing with pure base

Gloss is a measure of the ability of a coating surface to reflect a beam light at a particular angle without scattering. This is an important property of the coating, which is especially used for aesthetic and decorative purposes [1]. The final gloss of the cured samples is dependent on the UV light intensity used and cure time. Using a lamp with luminous intensity $130 \mathrm{mw}$ and radiation spectrum area $(\lambda=405 \mathrm{~nm})$ optimal cure time was found to be $30 \mathrm{~s}$. Samples without additives and with $1 \%$ of silica and $2 \%$ of NC showed medium gloss values 10-70 GU (gloss units) (Table 4 ), but samples with $2 \%$ of $\mathrm{CAB}$ and $2 \%$ of $\mathrm{SB}$ reached high gloss values $>70 \mathrm{GU}$. The increase of the gloss is more intense for the additives that are primarily film formers: $\mathrm{SB}$ and $\mathrm{CAB}$.

\section{CONCLUSIONS}

Using obtained data, optimal additive concentration has been found. $1 \%$ of silica and $2 \%$ of $\mathrm{CAB}$ and $\mathrm{NC}$ can provide stability of the suspension, were $2 \% \mathrm{TiO}_{2}$ and $0.01 \%$ red pigment is used. Compositions with $1 \%$ silica and $2 \% \mathrm{CAB}, \mathrm{SB}$ and $\mathrm{NC}$ conform the requested initial viscosity $(3000-4500 \mathrm{mPa})$. Degree of conversion is the most important parameter, which correlates with adhesion loss of the coating and film mechanical characteristics. All additives decrease degree of conversion, ultimate strength and effective soak off time in acetone. Biggest impact on pure base characteristics is obtained by $2 \%$ of NC and $2 \%$ of $\mathrm{CAB}$, which decrease effective soak off time on $60 \%$ and meet the requirements for coating removability (10 $\mathrm{min})$.

\section{Acknowledgments}

The authors thank the Investment and Development Agency of Latvia (Project No. LKC/2.1.2.1.1/10/01/006, Contract No. L-KC-11-0005) for their financial support.

\section{REFERENCES}

1. Jančovičová, V., Mikula, M., Havlinova, B., Jakubikova, Z. Influence of UV-Curing Conditions on Polymerization Kinetics and Gloss of Urethane Acrylate Coatings Progress in Organic Coatings 76 (2-3) 2013: pp. 432-438.

2. Wang, F., Hu, J.Q., Tu, W.P. Study on Microstructure of UV-Curable Polyurethane Acrylate Films Progress in Organic Coatings 62 2008: pp. 245-250. http://dx.doi.org/10.1016/j.porgcoat.2007.12.005

3. Milinavičiūtè, A., Jankauskaitè, V., Narmontas, $P$. Properties of UV-Curable Hyperbranched Urethane-Acrylate Modified Acrylic Monomer Coatings Materials Science (Medžiagotyra) 17 (4) 2011: pp. 378-383.

4. Džunuzovića, S.E., $\quad$ Tasićb, S.V., $\quad$ Božicc, B.R., Džunuzovićd, J.V., Dunjića, B.M., Jeremića, K.B. Mechanical and Thermal Properties of UV Cured Mixtures of Linear and Hyperbranched Urethane Acrylates Progress in Organic Coatings 74 (1) 2012: pp. 158-164.

5. Džunuzovića, S.E., Tasićb, S., Božicc, B., Babica, D., Dunjićb, B. UV-Curable Hyperbranched Urethane Acrylate Oligomers Containing Soybean Fatty Acids Progress in Organic Coatings 52 (2) 2005: pp. 136-143. http://dx.doi.org/10.1016/j.porgcoat.2004.10.003

6. Elya, C., Schneiderb, L.J., Ogliaria, F.A., Schmittd, C.C., Correae, I.C., Limaa, S.G., Samuelf, S.W., Pivaa, E. Polymerization Kinetics and Reactivity of Alternative Initiators Systems for Use in Light-Activated Dental Resins Dental Materials 2 (8) 2012: pp. 1199-1206. http://dx.doi.org/10.1016/j.dental.2012.08.009

7. Decker, C. The Use of UV Irradiation in Polymerization Polymer International 45 (2) 1999: pp. 133-141.

8. Johansson, M., Glauser, T., Jansson, A., Hult, A., Malmstrom, E., Claes, H. Design of Coating Resins by Changing the Macromolecular Architecture: Solid and Liquid Coating Systems Progress in Organic Coatings 48 (2-4) 2003: pp. 194-200.

9. Zamani, Y., Lahijania, K., Mohseni, M., Bastani, S. Characterization of Mechanical Behavior of UV Cured Urethane Acrylate Nanocomposite Films Loaded with Silane Treated Nanosilica by the Aid of Nanoindentation and Nanoscratch Experiments Tribology International 69 2014: pp. $10-18$.

10. Misbah, S., Mahmood, K.Z., Bhatti, H.N., Jamil, T., Hussain, R., Zuber, M. Modification of Cellulosic Fiber with Polyurethane Acrylate Copolymers. Part I: 
Physicochemical Properties Carbohydrate Polymers 2012: pp. 397-404.

http://dx.doi.org/10.1016/j.carbpol.2011.07.070

11. There's a Secret to Perfect Coatings And Inks: Hdk Pyrogenic Silica Wacker silicones, 2006.

12. Lenz, P., Hans, M., Luttikhedde, H. A Novel BiopolymerBased Coating Additive European Coatings Journal 5 (36-40) 2012: pp. 36-40.

13. Horacio, E.B., Roberts, O.W. Colloidal Silica: Fundamentals and Applications, Taylor and Francis, 2006.

14. Kim, K., Kim, M., Kim, J. Fabrication of UV-Curable Polyurethane Acrylate Composites Containing SurfaceModified Boron Nitride for Underwater Sonar Encapsulant Application Ceramics International 40 (7 B) 2014: pp. 10933 - 10943.

15. Fertier, L., Koleilat, H., Stemmelen, M., Giani, O., Duhamel, C.J., Lapinte, V., Robin, J.J. The Use of Renewable Feedstock in UV-Curable Materials - A New Age for Polymers and Green Chemistry Progress in Polymer Science 38 (6) 2013: pp. 932-962.

16. Lin, Y.H., Liao, K.H., Chou, N.K., Wang, S.S., Chu, S.H., Hsieh, K.H. UV-Curable Low-Surface-Energy Fluorinated Poly(urethane-acrylate)s for Biomedical Applications European Polymer Journal 44 (9) 2008: pp. 2927-2937.

17. Zhigang, C., Wu, J.F., Fernando, S., Jagodzinski, K. SoyBased, High Biorenewable Content UV Curable Coatings Progress in Organic Coatings 71 (1) 2011: pp. 98-109.

18. Lopaciuk, A., Loboda, M. Global Beauty Industry Trends in the 21st Century Managemant, Knowledge and Learning International Conference 2013: pp. 1079-1087.
19. Drummey, C. 2013-2014 Industry Statistics Highlights Nails Magazine 2013: pp. 3-32.

20. Vu, T., Chad, C. Compositions and Methods for Nail Coatings, United States Patent 20110182838, 28 July 2011.

21. Haile, D.L. Compositions for Removable Gel Applications for Nails and Methods of their Use, USA Patent WO 2011/011304 A2, 27 January 2011.

22. Koschar, M. Easily Removable Nail Polish Composition, Germany Patent DE102011102661 A1, 29 November 2012.

23. Learning By Doing: School Experiments With Wacker Silicones. Wacker silicones, Munchen, 2004: pp. 3-26.

24. Koleske, J.V. Paint and Coating Testing Manual. American Society for Testing and Materials, Philadelphia, 1995: pp. $28-140$.

25. Milinavičiūtè, A., Jankauskaitė, V., $\quad$ Fataraitè, E., Narmontas, P. Selection of Photopolymer for Microrelief Formation by Two-Stage Cold Stamping Method Materials Science (Medžiagotyra) 16 (3) 2010: pp. 210-216.

26. Determination of tensile properties. Part 3: Films and sheets, test conditions (in Latvian), BS EN ISO 527-3: 2000th Plastic.

27. Marzocca, A.J., Garazza, R.L., Mansilla, M.A. Evaluation of the Polymer-Solvent Interaction Parameter $\mathrm{x}$ for the System Cured Polybutadiene Rubber and Toluene Polymer Testing 29 2010: pp. 119-126.

28. Salamone, J.C. Polymeric Materials Encyclopedia, Twelve Volume Set, CRC Press, United States of America, 1996: pp. $22-89$. 